Supplement of Atmos. Chem. Phys., 22, 2203-2219, 2022

https://doi.org/10.5194/acp-22-2203-2022-supplement

(C) Author(s) 2022. CC BY 4.0 License.

(c) (1)

Atmospheric
Chemistry
and Physics

Supplement of

Investigations into the gas-phase photolysis and $\mathrm{OH}$ radical kinetics of nitrocatechols: implications of intramolecular interactions on their atmospheric behaviour

Claudiu Roman et al.

Correspondence to: Romeo Iulian Olariu (oromeo@uaic.ro)

The copyright of individual parts of the supplement might differ from the article licence. 
The present supplementary material (SM) aims to provide assistance for the obtained results with additional information supporting the reliable conclusions of the research study. The SM provides graphical illustration, details related to recorded data and instrumentation.

Figure $\mathbf{S 1}$ and Figure S2 present the gas-phase photolysis plots for 3-nitrocatechol and 5-methyl3-nitrocatechol at $365 \mathrm{~nm}$, and gas-phase photolysis plots for 4-nitrocatechol and 4-methyl-5nitrocatechol at $254 \mathrm{~nm}$. The photolysis rate constants were corrected for the wall loss $\left(\mathrm{k}_{4}\right)$, according to the reaction sequence presented in the manuscript.

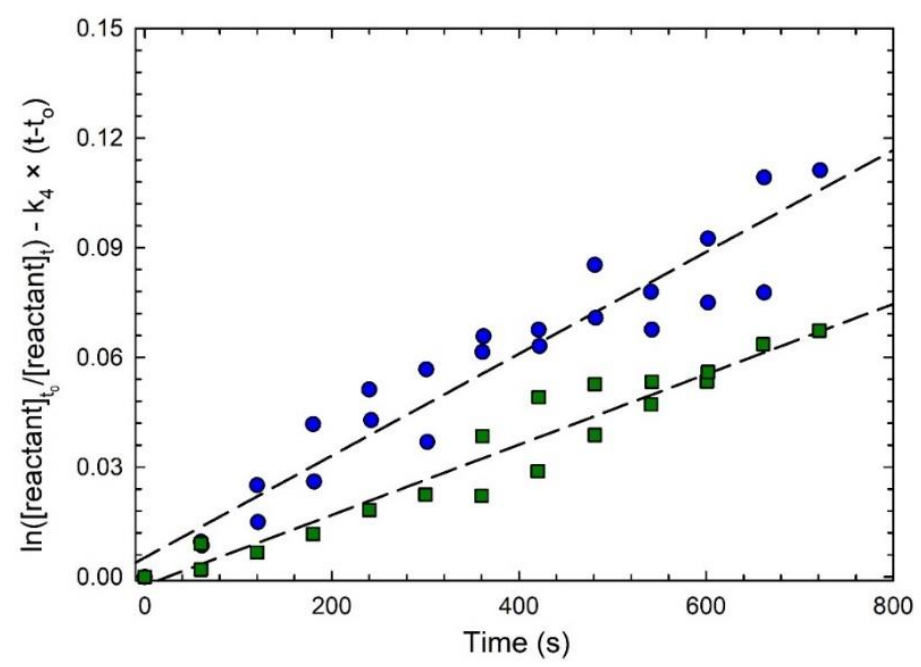

Figure S1: Kinetic plots according to the photolysis of $(\bullet)$ 3NCAT and $(\square)$ 5M3NCAT at $365 \mathrm{~nm}$ corrected for the wall loss, with $\mathrm{k}_{4}=(3.2 \pm 0.4) \times 10^{-4} \mathrm{~s}^{-1}$ (see details in the manuscript text).

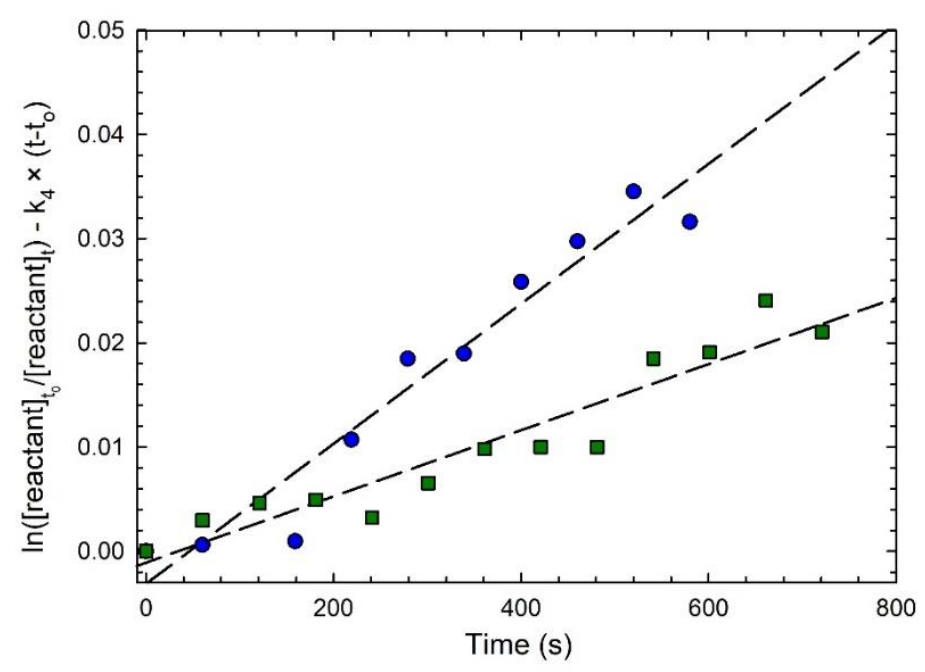

Figure S2: Kinetic plots according to the photolysis at $254 \mathrm{~nm}$ of $(\bullet)$ 4NCAT and ( $\square$ ) 4M5NCAT corrected for the wall loss, with $\mathrm{k}_{4}=(0.7 \pm 0.3) \times 10^{-4} \mathrm{~s}^{-1}$ (see details in the manuscript text).

Figure S3 illustrates the UV-Vis spectra for 3-nitrocatechol and 5-methyl-3-nitrocatechol and the calculated UV-Vis cross-sections. For comparison, the emission spectra of the used lamps emitting light in the range of $310-460 \mathrm{~nm}$ within maxima at $365 \mathrm{~nm}$ and recorded with an LI-COR spectroradiometer at a resolution of $1 \mathrm{~nm}$ inside the ESC-Q-UAIC chamber is given. The UV-Vis spectra for 3-nitrocatechol and 5- 
methyl-3-nitrocatechol from Figure S3 A and S3 B shows two intense absorption bands $(\lambda<250$ and $260>\lambda<350$ ) corresponding to a $\pi-\pi^{*}$ transition and one absorption band with a smaller intensity placed from 350 to $450 \mathrm{~nm}$ corresponding to $n-\pi^{*}$ transition in the 3-nitrocatechol molecule. Table S1 shows the values for the absorption cross sections $(\sigma)$ calculated in the $350-400 \mathrm{~nm}$ range (similar with the band intensity range emitted by the $365 \mathrm{~nm}$ lamps in the ESC-Q-UAIC reactor).

UV-Vis spectra of 3-nitrocatechol and 5-methyl-3-nitrocatechol, recorded in aqueous solution for the 220 - $500 \mathrm{~nm}$ wavelength range, were registered using a SPECORD 210 Plus UV-Vis spectrophotometer from Analytic Jena. Stock solution of $0.950 \mathrm{mg} / \mathrm{mL}$ of 3 NCAT and $0.568 \mathrm{mg} / \mathrm{mL}$ of 5 M3NCAT were used to obtain solutions by dilution over a large concentration range from $3.69 \times 10^{15}$ to $2.95 \times 10^{17} \mathrm{~cm}^{-3}$. The solution with five different concentrations were used to evaluate the absorption cross-sections.

Assuming similar cross-sections in the gas-phase with those in the aqueous solution, for the $350-400 \mathrm{~nm}$ photolytic range, an average quantum yield can be estimated using equation $\mathbf{S}_{\text {eq }} \mathbf{1}$ (Hofzumahaus et al., 1999). Using a boxcar integration method, the overall average quantum yields for this photolytic range $\left(\phi_{350-400}\right)$ are: $(7.707 \pm 0.737) \times 10^{-3}$ for 3 NCAT and $(4.858 \pm 0.464) \times 10^{-3}$ for $5 \mathrm{M} 3$ NCAT. The overall errors include contributions from the solution preparation, UV-Vis spectra recording and the photolysis value. The quantum yields values from the present study should be considered with caution, due to the charge transfer band of nitroaromatics which is known to undergo a considerable redshift by the change from gas-phase to solution and in thin film, and due to use of water as a solvent which is expected to provide largest shifts (Bejan, 2006; Reichardt and Welton, 2010).

$$
-\frac{d[A]}{d \mathrm{t}}=[A] \times J=[A] \times \int_{\lambda} \phi(\lambda) \sigma(\lambda) F(\lambda) d \lambda
$$
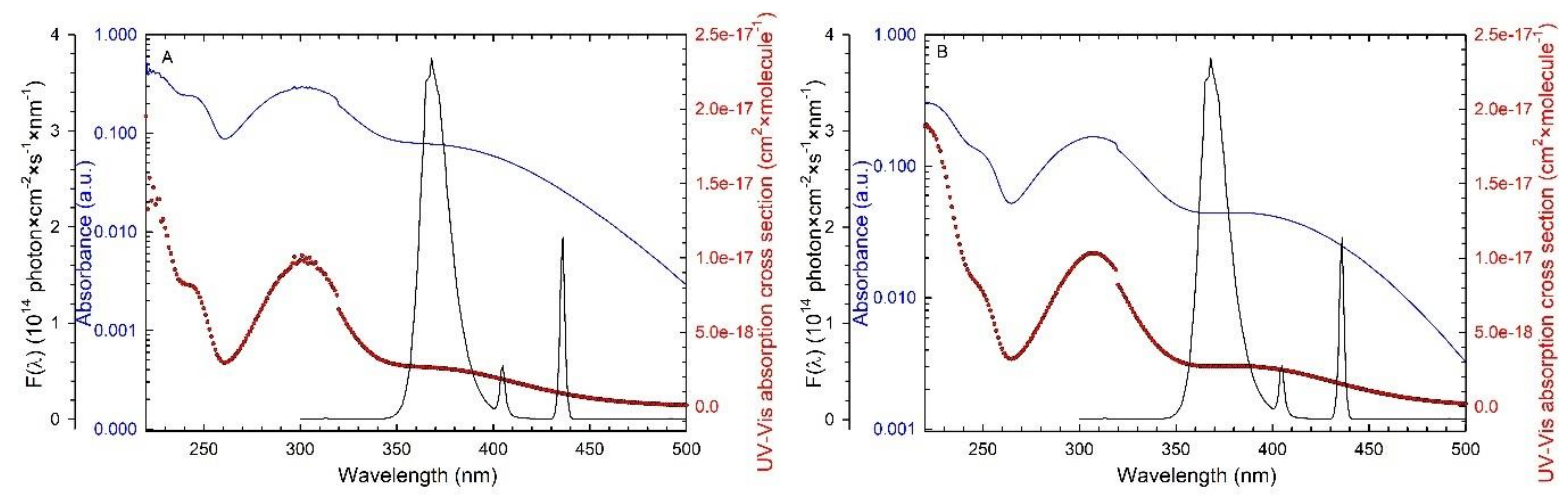

Figure S3: UV-Vis absorbance spectra of (A) 3NCAT and (B) 5M3NCAT in aqueous solution with the corresponding UV-Vis absorption cross sections (base 10) for 3NCAT and 5M3NCAT in the 220-500 nm range, along with the emission spectrum in the range of 300-500 nm of the Philips TL-DK $36 \mathrm{~W}$ lamps. 
Table S1: UV-Vis absorption cross section of 3NCAT and 5M3NCAT in aqueous solution in the 350-500 nm spectral range (base 10$)$ and the mean irradiance values of the actinic lamps ( $2 \pi$ sr acquisition mode) inside the ESC-Q-UAIC reactor.

\begin{tabular}{|c|c|c|c|c|c|c|c|}
\hline $\begin{array}{c}\lambda \\
(\mathrm{nm})\end{array}$ & $\begin{array}{c}\sigma_{3 \text { NCAT }} \times 10^{18} \\
\left(\mathrm{~cm}^{2} \times \text { molecule }^{-1}\right)\end{array}$ & $\begin{array}{c}\sigma_{5 \mathrm{M} 3 \mathrm{NCAT}} \times 10^{18} \\
\left(\mathrm{~cm}^{2} \times \text { molecule }^{-1}\right)\end{array}$ & $\begin{array}{c}\mathrm{E} \times 10^{-11} \\
\left(\text { photon } \times \mathrm{cm}^{-2}\right. \\
\times \mathrm{nm}^{-1} \times \mathrm{s}^{-1} \text { ) }\end{array}$ & $\begin{array}{c}\lambda \\
(n \mathrm{~nm})\end{array}$ & $\begin{array}{c}\sigma_{3 \mathrm{NCAT}} \times 10^{18} \\
\left(\mathrm{~cm}^{2} \times \text { molecule }^{-1}\right)\end{array}$ & $\begin{array}{c}\sigma_{5 M 3 N C A T} \times 10^{18} \\
\left(\mathrm{~cm}^{2} \times \text { molecule }^{-1}\right)\end{array}$ & 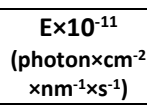 \\
\hline 350 & 2.82 & 3.16 & 1.30 & 426 & 1.16 & 1.87 & 3.19 \\
\hline 351 & 2.80 & 3.10 & 0.82 & 427 & 1.13 & 1.83 & 3.43 \\
\hline 352 & 2.78 & 3.04 & 1.22 & 428 & 1.10 & 1.80 & 3.26 \\
\hline 353 & 2.76 & 3.00 & 1.01 & 429 & 1.08 & 1.77 & 3.25 \\
\hline 354 & 2.74 & 2.95 & 1.58 & 430 & 1.05 & 1.73 & 3.35 \\
\hline 355 & 2.73 & 2.91 & 0.73 & 431 & 1.02 & 1.70 & 7.84 \\
\hline 356 & 2.72 & 2.88 & 0.88 & 432 & 0.99 & 1.67 & 38.13 \\
\hline 357 & 2.71 & 2.85 & 0.49 & 433 & 0.97 & 1.63 & 122.32 \\
\hline 358 & 2.70 & 2.82 & 0.78 & 434 & 0.94 & 1.60 & 327.30 \\
\hline 359 & 2.69 & 2.80 & 0.27 & 435 & 0.91 & 1.56 & 773.47 \\
\hline 360 & 2.68 & 2.78 & 0.72 & 436 & 0.89 & 1.53 & 946.83 \\
\hline 361 & 2.67 & 2.77 & 1.51 & 437 & 0.86 & 1.49 & 564.43 \\
\hline 362 & 2.67 & 2.75 & 4.57 & 438 & 0.83 & 1.46 & 209.74 \\
\hline 363 & 2.66 & 2.74 & 8.52 & 439 & 0.81 & 1.42 & 71.36 \\
\hline 364 & 2.66 & 2.73 & 6.50 & 440 & 0.79 & 1.39 & 14.72 \\
\hline 365 & 2.65 & 2.73 & 2.49 & 441 & 0.76 & 1.36 & 3.00 \\
\hline 366 & 2.64 & 2.73 & 1.22 & 442 & 0.74 & 1.33 & 2.34 \\
\hline 367 & 2.63 & 2.72 & 0.57 & 443 & 0.72 & 1.30 & 2.13 \\
\hline 368 & 2.63 & 2.72 & 0.87 & 444 & 0.70 & 1.27 & 2.30 \\
\hline 369 & 2.62 & 2.72 & 0.77 & 445 & 0.68 & 1.24 & 2.16 \\
\hline 370 & 2.61 & 2.72 & 0.54 & 446 & 0.66 & 1.21 & 2.22 \\
\hline 371 & 2.60 & 2.73 & 0.37 & 447 & 0.64 & 1.18 & 1.98 \\
\hline 372 & 2.59 & 2.73 & 0.51 & 448 & 0.62 & 1.15 & 1.99 \\
\hline 373 & 2.58 & 2.73 & 0.85 & 449 & 0.60 & 1.11 & 1.97 \\
\hline 374 & 2.57 & 2.73 & 0.82 & 450 & 0.58 & 1.08 & 1.96 \\
\hline 375 & 2.56 & 2.74 & 0.48 & 451 & 0.56 & 1.05 & 2.01 \\
\hline 376 & 2.54 & 2.74 & 0.75 & 452 & 0.54 & 1.03 & 1.96 \\
\hline 377 & 2.53 & 2.74 & 0.87 & 453 & 0.53 & 1.00 & 1.79 \\
\hline 378 & 2.51 & 2.74 & 0.57 & 454 & 0.51 & 0.97 & 1.89 \\
\hline 379 & 2.50 & 2.74 & 0.43 & 455 & 0.49 & 0.94 & 1.75 \\
\hline 380 & 2.48 & 2.74 & 0.59 & 456 & 0.48 & 0.92 & 1.78 \\
\hline 381 & 2.46 & 2.74 & 1.04 & 457 & 0.47 & 0.90 & 1.79 \\
\hline 382 & 2.45 & 2.74 & 1.06 & 458 & 0.45 & 0.87 & 1.84 \\
\hline 383 & 2.43 & 2.74 & 1.58 & 459 & 0.44 & 0.85 & 1.80 \\
\hline 384 & 2.41 & 2.74 & 2.23 & 460 & 0.42 & 0.82 & 1.78 \\
\hline 385 & 2.38 & 2.74 & 2.16 & 461 & 0.41 & 0.80 & 1.77 \\
\hline 386 & 2.36 & 2.73 & 1.59 & 462 & 0.39 & 0.77 & 1.70 \\
\hline 387 & 2.34 & 2.73 & 0.74 & 463 & 0.38 & 0.75 & 1.84 \\
\hline 388 & 2.32 & 2.73 & 1.38 & 464 & 0.37 & 0.72 & 1.75 \\
\hline 389 & 2.30 & 2.72 & 1.58 & 465 & 0.36 & 0.70 & 1.84 \\
\hline 390 & 2.27 & 2.71 & 1.70 & 466 & 0.34 & 0.68 & 1.78 \\
\hline 391 & 2.25 & 2.71 & 2.11 & 467 & 0.33 & 0.66 & 1.78 \\
\hline 392 & 2.22 & 2.70 & 2.45 & 468 & 0.32 & 0.64 & 1.65 \\
\hline 393 & 2.19 & 2.69 & 2.91 & 469 & 0.31 & 0.62 & 1.74 \\
\hline 394 & 2.16 & 2.68 & 5.53 & 470 & 0.30 & 0.60 & 1.74 \\
\hline 395 & 2.14 & 2.66 & 6.90 & 471 & 0.29 & 0.58 & 1.69 \\
\hline 396 & 2.11 & 2.65 & 9.17 & 472 & 0.28 & 0.56 & 1.80 \\
\hline 397 & 2.08 & 2.64 & 11.65 & 473 & 0.27 & 0.54 & 1.67 \\
\hline 398 & 2.05 & 2.62 & 14.77 & 474 & 0.26 & 0.52 & 1.77 \\
\hline 399 & 2.02 & 2.61 & 25.67 & 475 & 0.25 & 0.51 & 1.63 \\
\hline 400 & 1.99 & 2.59 & 28.78 & 476 & 0.24 & 0.49 & 1.61 \\
\hline 401 & 1.96 & 2.56 & 44.73 & 477 & 0.23 & 0.47 & 1.73 \\
\hline 402 & 1.93 & 2.55 & 60.73 & 478 & 0.23 & 0.46 & 1.70 \\
\hline 403 & 1.90 & 2.53 & 80.00 & 479 & 0.22 & 0.44 & 1.73 \\
\hline 404 & 1.87 & 2.51 & 120.45 & 480 & 0.21 & 0.42 & 1.62 \\
\hline 405 & 1.84 & 2.48 & 165.19 & 481 & 0.20 & 0.41 & 1.68 \\
\hline 406 & 1.80 & 2.46 & 223.60 & 482 & 0.19 & 0.40 & 1.64 \\
\hline 407 & 1.77 & 2.44 & 289.32 & 483 & 0.19 & 0.38 & 1.76 \\
\hline 408 & 1.74 & 2.41 & 423.36 & 484 & 0.18 & 0.37 & 1.69 \\
\hline
\end{tabular}




\begin{tabular}{|c|c|c|c|c|c|c|c|}
\hline 409 & 1.70 & 2.39 & 535.28 & 485 & 0.17 & 0.36 & 1.77 \\
\hline 410 & 1.67 & 2.36 & 681.85 & 486 & 0.17 & 0.34 & 1.73 \\
\hline 411 & 1.64 & 2.33 & 838.44 & 487 & 0.16 & 0.33 & 1.83 \\
\hline 412 & 1.60 & 2.30 & 1090.00 & 488 & 0.16 & 0.32 & 1.92 \\
\hline 413 & 1.57 & 2.28 & 1289.25 & 489 & 0.15 & 0.31 & 2.42 \\
\hline 414 & 1.54 & 2.25 & 1458.40 & 490 & 0.14 & 0.30 & 3.16 \\
\hline 415 & 1.51 & 2.22 & 1754.08 & 491 & 0.14 & 0.28 & 4.95 \\
\hline 416 & 1.48 & 2.19 & 1768.50 & 492 & 0.13 & 0.27 & 5.23 \\
\hline 417 & 1.45 & 2.16 & 1781.33 & 493 & 0.13 & 0.26 & 3.52 \\
\hline 418 & 1.41 & 2.13 & 1876.48 & 494 & 0.12 & 0.25 & 2.41 \\
\hline 419 & 1.38 & 2.10 & 1809.75 & 495 & 0.12 & 0.24 & 1.90 \\
\hline 420 & 1.35 & 2.07 & 1767.25 & 496 & 0.11 & 0.23 & 1.76 \\
\hline 421 & 1.32 & 2.03 & 1712.93 & 497 & 0.11 & 0.23 & 1.61 \\
\hline 422 & 1.28 & 2.00 & 1680.45 & 498 & 0.11 & 0.22 & 1.61 \\
\hline 423 & 1.25 & 1.97 & 1556.10 & 499 & 0.10 & 0.21 & 1.64 \\
\hline 424 & 1.22 & 1.93 & 1439.23 & 500 & 0.10 & 0.20 & 1.66 \\
\hline 425 & 1.19 & 1.90 & 1358.03 & & & & \\
\hline
\end{tabular}

In an attempt to preliminary evaluate the gas-phase products formed from the photolysis and from the $\mathrm{OH}$ radical initiated gas-phase oxidation of nitrocatechols, the infrared spectra for these reactions were evaluated. No ring-retaining or ring-opening products were identified from the photolysis or photooxidation of the investigated nitrocatechols. However, the residual photolysis product spectra illustrated in Figure S4 show clear absorption features at $2139 \mathrm{~cm}^{-1}$ for 3NCAT and $2135 \mathrm{~cm}^{-1}$ for 5M3NCAT. The photolysis mechanism of nitroaromatic compounds leading to the formation of a ketenetype product and HONO elimination has been previously proposed (Bejan et al., 2020), similar to the carboxylic acid formation mechanism in aqueous phase proposed by Alif et al. (1991).

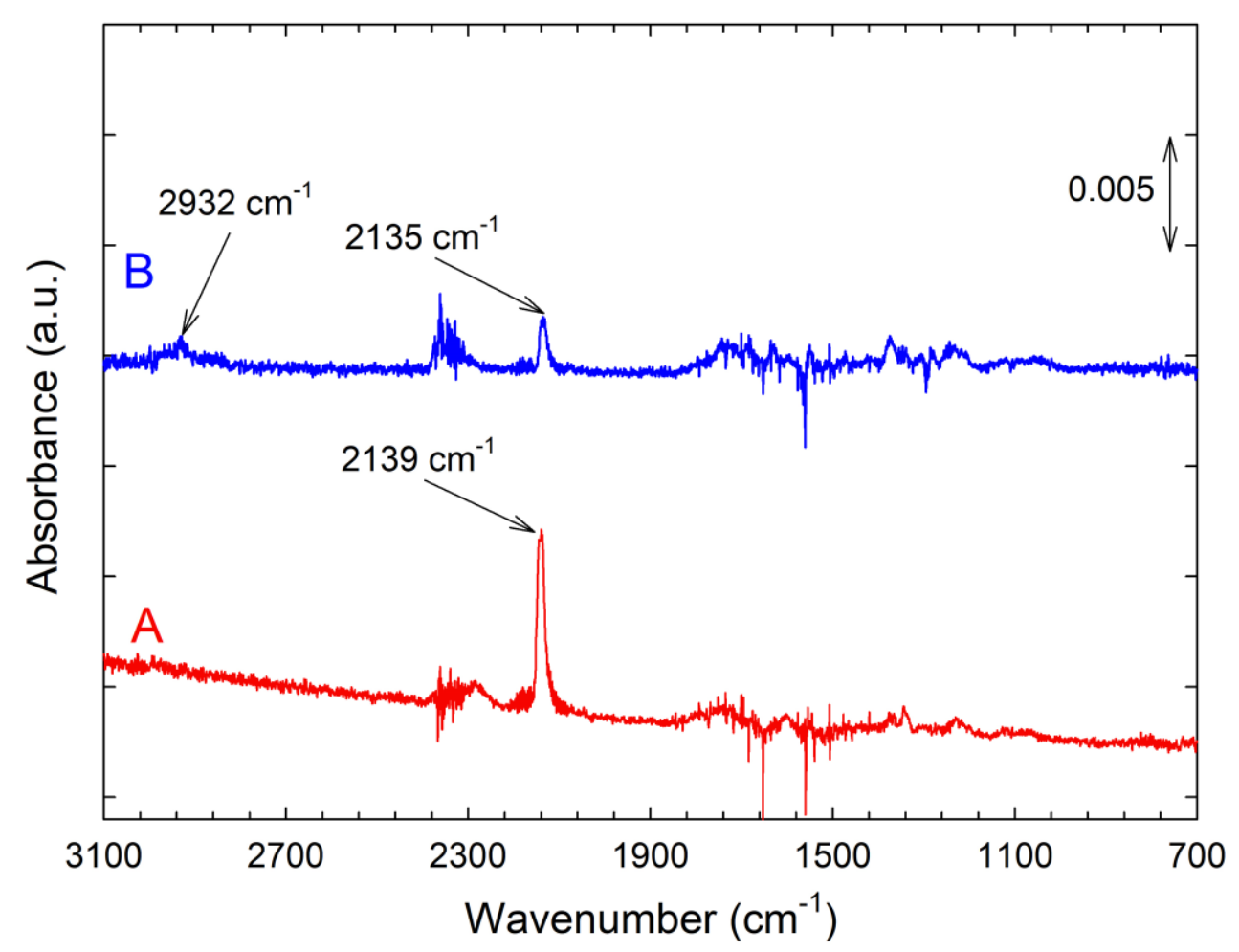

Figure S4: Residual spectra from the gas-phase photolysis of (A) 3NCAT and (B) 5M3NCAT at $365 \mathrm{~nm}$. 
Additionally, the intramolecular $\mathrm{H}$-bond formed between the phenolic $\mathrm{H}$ and $\mathrm{O}$-atom from the nitro group can be observed by investigating the gas-phase IR spectra of 2-, 3-, and 4-nitrophenols presented in Figure S5. Bejan (2006) has presented similar findings for 2-nitrophenol in comparison with 3- and 4-nitrophenol isomers. Figure $\mathbf{S 5}$ adds even more spectral evidence with the main aim to highlight the differences between the $\mathrm{OH}$ band position in the gas-phase IR spectra of phenol, 2-methyl-3nitrophenol and 4-nitrophenol with those from 2-nitrophenols. Spectral shifts up to $350 \mathrm{~cm}^{-1}$ were observed between the $\mathrm{OH}$ band positions.

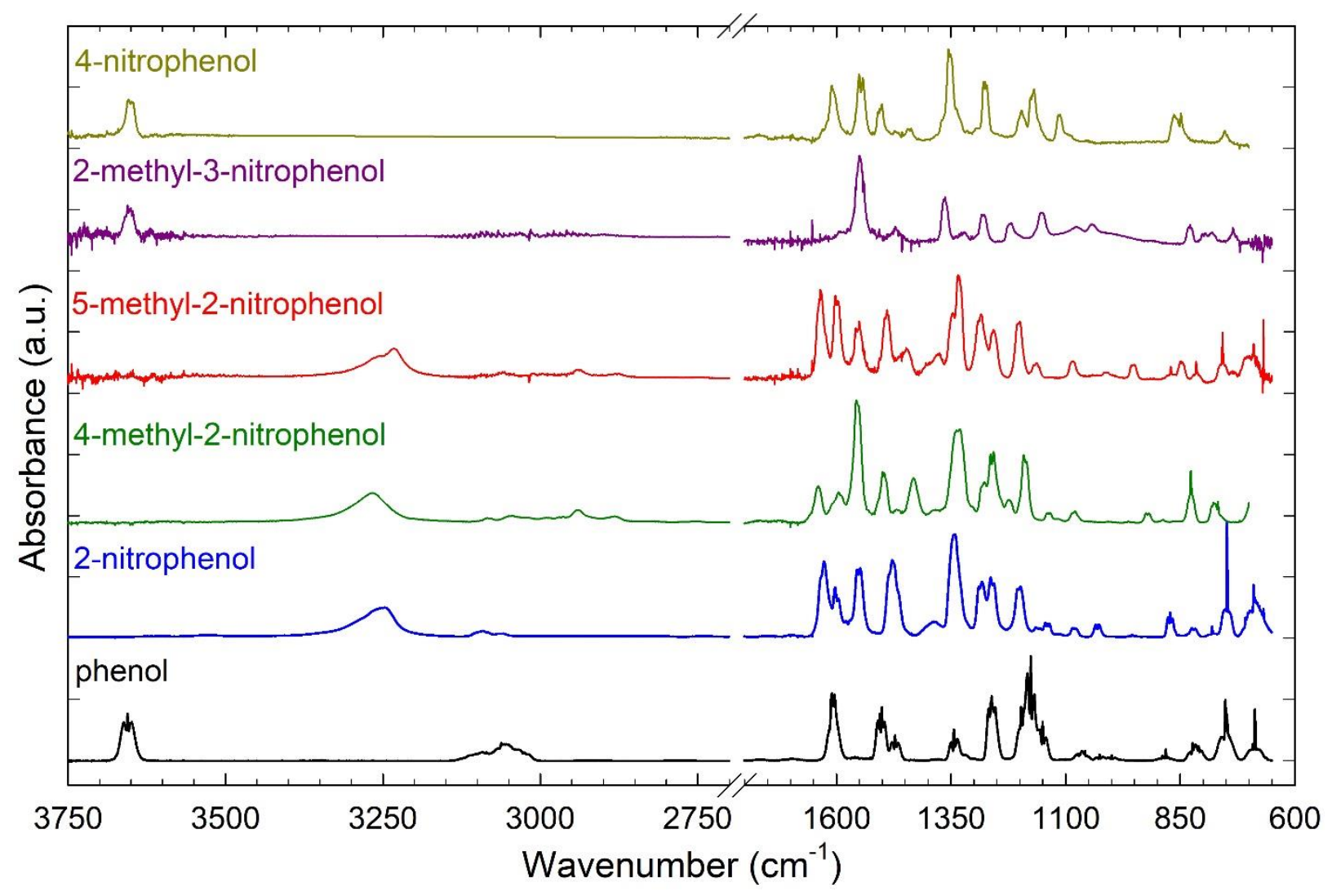

Figure S5: Gas-phase IR spectra of phenol, several 2-nitrophenols, 2-methyl-3-nitrophenol and 4nitrophenol. 
The substituents interactions and their influence in the gas-phase $\mathrm{OH}$-reactivity of nitrocatechols and nitrophenols were extensively discussed in the manuscript. Additionally, Table S2 presents the updated values of Kwok and Atkinson (1995) SAR method with respect to the electrophilic substituents $\mathrm{\sigma}_{\mathrm{i}}^{+}$contribution used in estimation of the $\mathrm{KOH}$ addition pathway and considerations given in other investigations (Brown and Okamoto, 1958; Zetzsch, 1982; Rinke and Zetzsch, 1984). In the case of 3nitrocatechol and 5-methyl-3-nitrocatechol, the value with the most negative $\Sigma \sigma_{i}{ }^{+}$corresponds to $o$ - and $p$ - positions relative to the $\mathrm{NO}_{2}$ substituent group. This is attributed to the fact that the $\mathrm{OH}$ placed next to the $\mathrm{NO}_{2}$ could not influence the addition pathway since its shielding prevails. Very good estimated rate values are obtained in using this attempt for 3NCAT, 5M3NCAT and 4M5NCAT. However, for 4NCAT and nitrophenols this updated estimation tends to under evaluate the experimental data. Unfortunately, given the fact that in the catechol structure, the second $\mathrm{OH}$ group has no contribution to the addition pathway, the $\sigma^{+}$for meta and/or ipso positions being neglected, no relevant new updated values could be now performed for $\sigma^{+}$for the lone-pair $\mathrm{NO}_{2}$ substituents.

Table S2: Rate coefficients for the reaction of nitroaromatic compounds with $\mathrm{OH}$ radicals at room temperature calculated from Kwok and Atkinson (1995) SAR updated for the internal effects observed in nitrophenols and nitrocatechols, along with the electrophilic substituents constants proposed by Brown and Okamoto (1958) and Zetzsch (1982).

\begin{tabular}{|c|c|c|c|c|}
\hline Compound & $\sigma_{i}^{+}$ & $\Sigma \sigma_{i}^{+}$ & $\mathrm{k}_{\mathrm{abs}} \times 10^{13}$ & $\begin{array}{c}\mathrm{k} \times 10^{12} \\
\left(\mathrm{~cm}^{3} \times \mathrm{s}^{-1}\right)\end{array}$ \\
\hline Nitrobenzene & $0.674\left[\mathrm{~m}-\left(\mathrm{NO}_{2}\right)\right]$ & 0.674 & - & 0.244 \\
\hline \multirow[t]{2}{*}{ m-nitrotoluene } & $-0.311\left[\mathrm{p}-\left(\mathrm{CH}_{3}\right)\right]$ & 0.479 & $1.36\left(\mathrm{CH}_{3}\right)$ & 0.581 \\
\hline & $0.79[p-(N O 2)]$ & & & \\
\hline 2-nitrophenol & $0.674\left[\mathrm{~m}-\left(\mathrm{NO}_{2}\right)\right]$ & 0.674 & - & 0.244 \\
\hline \multirow[t]{2}{*}{ 3-methyl-2-nitrophenol } & $-0.311\left[\mathrm{p}-\left(\mathrm{CH}_{3}\right)\right]$ & 0.363 & $1.36\left(\mathrm{CH}_{3}\right)$ & 0.772 \\
\hline & $0.674\left[\mathrm{~m}-\left(\mathrm{NO}_{2}\right)\right]$ & & & \\
\hline \multirow[t]{2}{*}{ 5-methyl-2-nitrophenol } & $-0.311\left[\mathrm{p}-\left(\mathrm{CH}_{3}\right)\right]$ & 0.363 & $1.36\left(\mathrm{CH}_{3}\right)$ & 0.772 \\
\hline & $0.674\left[\mathrm{~m}-\left(\mathrm{NO}_{2}\right)\right]$ & & & \\
\hline \multirow[t]{2}{*}{ 4-methyl-2-nitrophenol } & $-0.311\left[\mathrm{p}-\left(\mathrm{CH}_{3}\right)\right]$ & 0.479 & $1.36\left(\mathrm{CH}_{3}\right)$ & 0.581 \\
\hline & $0.79\left[\mathrm{p}-\left(\mathrm{NO}_{2}\right)\right]$ & & & \\
\hline \multirow[t]{2}{*}{ 6-methyl-2-nitrophenol } & $-0.311\left[\mathrm{p}-\left(\mathrm{CH}_{3}\right)\right]$ & 0.479 & $1.36\left(\mathrm{CH}_{3}\right)$ & 0.581 \\
\hline & $0.79\left[\mathrm{p}-\left(\mathrm{NO}_{2}\right)\right]$ & & & \\
\hline \multirow[t]{2}{*}{ 3-nitrocatechol } & $-0.92[\mathrm{o}-(\mathrm{OH})]$ & -0.130 & $1.4(\mathrm{OH})$ & 3.052 \\
\hline & $0.79\left[\mathrm{p}-\left(\mathrm{NO}_{2}\right)\right]$ & & & \\
\hline 4-nitrocatechol & $0.674\left[\mathrm{~m}-\left(\mathrm{NO}_{2}\right)\right]$ & 0.674 & $1.4(\mathrm{OH})$ & 0.384 \\
\hline \multirow[t]{3}{*}{ 5-methyl-3-nitrocatechol } & $-0.92[\mathrm{o}-(\mathrm{OH})]$ & -0.441 & $1.4(\mathrm{OH})$ & 7.878 \\
\hline & $-0.311\left[\mathrm{p}-\left(\mathrm{CH}_{3}\right)\right]$ & & $1.36\left(\mathrm{CH}_{3}\right)$ & \\
\hline & $0.79[p-(N O 2)]$ & & & \\
\hline \multirow[t]{2}{*}{ 4-methyl-5-nitrocatechol } & $-0.311\left[\mathrm{p}-\left(\mathrm{CH}_{3}\right)\right]$ & 0.363 & $1.4(\mathrm{OH})$ & 0.912 \\
\hline & $0.674\left[\mathrm{~m}-\left(\mathrm{NO}_{2}\right)\right]$ & & $1.36\left(\mathrm{CH}_{3}\right)$ & \\
\hline
\end{tabular}




\section{List of references:}

Alif, A., Pilichowski, J. F., and Boule, P.: Photochemistry and environment XIII: Phototransformation of 2nitrophenol in aqueous solution, J. Photochem. Photobiol. A Chem., 59, 209-219, https://doi.org/10.1016/1010-6030(91)87009-K, 1991.

Bejan, I., Olariu, R., and Wiesen, P.: Secondary organic aerosol formation from nitrophenols photolysis under atmospheric conditions, Atmosphere (Basel)., 11, 1346, https://doi.org/10.3390/atmos11121346, 2020.

Bejan, I. G.: Investigations on the gas phase atmospheric chemistry of nitrophenols and catechols, Bergische Universität Wuppertal, 2006.

Brown, H. and Okamoto, Y.: Electrophilic substituent constants, J. Am. Chem. Soc., 80, 4979-4987, 1958.

Finlayson-Pitts, B. J. and Pitts, J. N.: Chemistry of the upper and lower atmosphere, Academic Press, https://doi.org/10.1016/B978-012257060-5/50007-1, 2000.

Hofzumahaus, A., Kraus, A., and Müller, M.: Solar actinic flux spectroradiometry: a technique for measuring photolysis frequencies in the atmosphere, Appl. Opt., 38, 4443, https://doi.org/10.1364/ao.38.004443, 1999.

Kwok, E. and Atkinson, R.: Estimation of hydroxyl radical reaction rate constants for gas-phase organic compounds using a structure-reactivity relationship: An update, Atmos. Environ., 29, 1685-1695, https://doi.org/10.1016/1352-2310(95)00069-B, 1995.

Reichardt, C., Welton, T.: Solvents and Solvent Effects in Organic Chemistry, 4th ed., Wiley-VCH Verlag GmbH, 677-692 pp., https://doi.org/10.1002/9783527632220.indsub, 2010.

Rinke, M. and Zetzsch, C.: Rate constants for the reactions of $\mathrm{OH}$ radicals with aromatics: benzene, phenol, aniline, and 1,2,4-trichlorobenzene, Berichte der Bunsengesellschaft für Phys. Chemie, 88, 5562, https://doi.org/10.1002/bbpc.19840880114, 1984.

Zetzsch, C.: Predicting the rate of $\mathrm{OH}$-addition to aromatics using $\sigma+$-electrophilic substituents constants for mono- and polysubstituted benzene, in: $\mathrm{XI}^{\text {th }}$ Informal Conference on Photochemistry, Stanford, California, 27. 6. - 1. 7, 1982. 